Boise State University

ScholarWorks

Mathematics Faculty Publications and

Presentations

Department of Mathematics

$12-2017$

\title{
Statistics as Unbiased Estimators: Exploring the Teaching of Standard Deviation
}

\author{
Nicholas H. Wasserman \\ Columbia University \\ Stephanie Casey \\ Eastern Michigan University \\ Joe Champion \\ Boise State University \\ Maryann Huey \\ Drake University
}


This is an author-produced, peer-reviewed version of this article. The final, definitive version of this document can be found online at Research

in Mathematics Education, published by Routledge. Copyright restrictions may apply. doi: 10.1080/14794802.2017.1333918

\title{
Statistics as Unbiased Estimators: Exploring the Teaching of Standard Deviation
}

\author{
Nicholas H. Wasserman \\ Department of Mathematics, Science, and Technology \\ Teachers College, Columbia University \\ New York, NY, USA \\ Stephanie Casey \\ Department of Mathematics \\ Eastern Michigan University \\ Ypsilanti, MI, USA \\ Joe Champion \\ Department of Mathematics \\ Boise State University \\ Boise, ID, USA \\ Maryann Huey \\ Department of Mathematics and Computer Science \\ Drake University \\ Des Moines, IA, USA
}

\begin{abstract}
This manuscript presents findings from a study about the knowledge for and planned teaching of standard deviation. We investigate how understanding variance as an unbiased (inferential) estimator - not just a descriptive statistic for the variation (spread) in data - is related to teachers' instruction regarding standard deviation, particularly around the issue of division by $n-1$. In this regard, the study contributes to our understanding about how knowledge of mathematics beyond the current instructional level, what we refer to as nonlocal mathematics, becomes important for teaching. The findings indicate that acquired knowledge of nonlocal mathematics can play a role in altering teachers' planned instructional approaches in terms of student activity and cognitive demand in their instruction.
\end{abstract}

Keywords: standard deviation, unbiased estimator, statistical knowledge for teaching

\section{Introduction}

Content knowledge for teaching is, increasingly, viewed through a practice-based lens (e.g., Ball, Thames \& Phelps, 2008; Rowland, Huckstep \& Thwaites, 2005), where such knowledge must have implications for teachers' professional work. Although knowing content beyond what is being taught is generally valued, understanding precisely how this additional knowledge interacts with teaching is less clear. Some have argued that further expertise might become a "blind spot" for teachers (Nathan \& Petrosino, 2003), whereas others have described potential benefits, such as avoiding reductionist approaches that create misconception-based obstacles for future learning (e.g., Wasserman \& Stockton, 2013; Zazkis \& Mamolo, 2011).

In this paper, we examine this with respect to planned instructional practices in statistics, an increasingly important content area due to greater incorporation in school mathematics (e.g., CCSSI, 2010). In the field of statistics, a "statistic" is often used to describe certain features of a dataset; for example, typical value (measures of central tendency) or typical variation (measures of spread). However, the field of statistics is not just concerned with description but is also concerned with inference: taking what is known from a sample to infer something about the larger population. This exploratory study investigates various ways teachers plan to address division by $n-1$ in teaching 
This is an author-produced, peer-reviewed version of this article. The final, definitive version of this document can be found online at Research in Mathematics Education, published by Routledge. Copyright restrictions may apply. doi: 10.1080/14794802.2017.1333918

the standard deviation statistic, and how responses indicative of sample variance as an unbiased estimator of a population parameter (inference) may be related to intended teaching approaches, drawing implications for teacher education.

\section{Literature}

\section{Conceptual Framework}

Various frameworks have helped characterize how mathematical knowledge impacts teaching practice (e.g., Ball, Thames, \& Phelps, 2008; Rowland, Huckstep, \& Thwaites, 2005). The field in general recognizes that one's knowledge of mathematics is influential on their instructional approaches to teaching; in this study, we are particularly concerned within examining the potential role of mathematical knowledge beyond what one teaches. We adopt as our conceptual framework Wasserman's (2016a; 2016b) work regarding a teacher's perspective on the mathematical landscape: local describes mathematics that is in a local neighborhood of the mathematics being taught and nonlocal describes mathematics outside that neighborhood. That is, we consider mathematical ideas within a topological space, where those that are close to the content being taught are within the local neighborhood, and those further away are outside this local neighborhood. "Close" in this sense entails both the degree to which mathematical ideas are closely connected as well as temporally close in relation to when mathematical ideas are typically developed. Wasserman's nonlocal neighborhood is similar to Ball, Thames, and Phelps' (2008) horizon content knowledge within their mathematical knowledge for teaching (MKT) framework.

While it is obvious that teachers' knowledge of local mathematics would influence their teaching of local mathematics (i.e., a teacher must know the content that they teach), it is less clear how knowledge of nonlocal mathematics might also influence the teaching of local mathematics (see Figure 1). In particular, we are interested on its influence on the cognitive demand and student activity in teachers' planned lessons. Stein, Smith, Henningsen, and Silver (2009) articulated a hierarchy of tasks according to their cognitive demand on students: i) memorization tasks, ii) procedureswithout-connections tasks, iii) procedures-with-connections tasks, and iv) doing-mathematics tasks. Activities that involve students "doing" mathematics in a connected way (iii and iv) are more cognitively demanding than students practicing procedures or memorizing facts (i and ii). Indeed, part of planning lessons involves designing ways for students to interact with mathematics, which at times may be the teacher explaining mathematical ideas with students in a predominantly passive role, and at other times may be tasks that actively engage students in "doing." As such, the level of cognitive demand placed upon students is often entangled with their activity level. Returning to our study, in the teaching of local mathematics, we ask: is there a relationship between the cognitive demand and student activity of teachers' planned lessons and their knowledge of nonlocal mathematics?

[Insert Figure 1. Research framework exploring relationship between knowledge of nonlocal mathematics and local teaching]

\section{$\underline{\text { Standard Deviation in Secondary Mathematics Education }}$}

Mathematics teachers are primarily responsible for teaching statistics at pre-university levels. Standard deviation, in particular, is part of the secondary mathematics curriculum in countries throughout the world (e.g., Brazil- Ministério da Educação, 2006; South Africa-Department of Education, 2002; USA-CCSSI, 2010). These curriculum standards emphasize the descriptive use of standard deviation to measure and describe the variability of a distribution. For example, in the USA, secondary students are expected to learn about standard deviation as a measure of variability in order to compare the spread of multiple data sets and interpret any differences (CCSSI, 2010 - see HSS.ID.A.2\&3). Understanding variation is fundamental to statistical thinking (Wild \& Pfannkuch, 1999); thus, understanding standard deviation as a measure of variability is an important learning goal for students. 
This is an author-produced, peer-reviewed version of this article. The final, definitive version of this document can be found online at Research in Mathematics Education, published by Routledge. Copyright restrictions may apply. doi: 10.1080/14794802.2017.1333918

Regarding the population standard deviation, $\sigma=\sqrt{\frac{1}{n} \sum_{i=1}^{n}\left(x_{i}-\mu\right)^{2}}$

sample to the (corrected) sample standard deviation, $s=\sqrt{\frac{1}{n-1} \sum_{i=1}^{n}\left(x_{i}-\bar{x}\right)^{2}}$. (We do note that there are other approaches for estimating the standard deviation of a population from a sample, such as maximum likelihood estimators, shrinkage estimators, etc.) Variance, which is the square of standard deviation, has a completely unbiased estimator (e.g., Ramachandran \& Tsokos, 2009); however, since square roots do not commute with expected values, there is no completely unbiased estimator for standard deviation that is independent of the underlying distribution. Yet, the unbiased estimator of variance greatly reduces the bias in the standard deviation estimate; therefore, it is frequently used as the basis for the (corrected) sample standard deviation calculation.

Research about the knowledge teachers need for teaching about variability is urgently needed, as extant work has not looked at teacher knowledge as distinct from student knowledge (Sánchez, da Silva \& Coutinho, 2011). For standard deviation in particular, we contend that teachers need to know statistics from both a descriptive and inferential standpoint. At the secondary level, however, teachers (at least in the USA) are primarily responsible for teaching students about the descriptive role of statistics (e.g., CCSSI, 2010); hence, the local mathematics concerns descriptive statistics. Inferential notions of statistics, then, are part of the nonlocal neighborhood. Yet, for teachers to teach students how to compute standard deviation in a way that supports reasoning and sense making (NCTM, 2014), they need to explain the reasoning behind why it is computed in that way, which draws on notions of inference. Thus, it is important for a teacher to understand why the distinction between sample and population is significant and how that distinction yields potentially ${ }^{\mathrm{i}}$ different formulas for standard deviation in inferential and descriptive settings (i.e., division by $n-1$ versus division by $n$ ).

\section{Methodology}

The focus of this exploratory study was to answer the research questions: In what ways do teachers' plan for teaching standard deviation, particularly for addressing the issue of division by $n-1$ ? And what role does understanding statistics as estimators of population parameters play in their plans? To address this, a qualitative study with an intervention methodology was conducted to collect information about secondary mathematics teachers' content knowledge and plans for teaching standard deviation. Participants: i) designed a lesson about standard deviation; ii) participated in a 90-minute Unbiased Estimator Lesson (UEL); and iii) were interviewed, which included both a content assessment and interview questions about their planned lesson.

\section{$\underline{\text { Participants }}$}

Secondary mathematics teachers in the USA enrolled in mathematics methods courses at three large universities or participating in a professional development course regarding the teaching of statistics at a different site were potential participants for the study. Each course enrolled teachers with a range of teaching experiences and differing mathematical and statistical backgrounds. From all teachers, potential participants from each of the four sites were purposefully selected based on the results of an initial content knowledge assessment (described further in the Data section). Teachers who could not provide an accurate, descriptive interpretation of standard deviation on the assessment were removed from consideration; this ensured that potential participants had a minimal level of knowledge about standard deviation. Among those remaining, as is common in exploratory studies (e.g., Yin, 2014), the researchers purposefully sought to include a diverse group regarding their responses about and potential meanings for standard deviation, as well as their backgrounds in teaching. Potential participants were contacted; ultimately sixteen (8 preservice, 8 inservice) agreed to participate in the study.

\section{Unbiased Estimators Lesson}

In accord with our theoretical perspective, we were interested in how knowledge of nonlocal mathematics interacted with the teaching of local mathematics; specifically, the role that nonlocal knowledge of statistics as inferential estimators of population parameters played in the planned teaching of local content concerning standard deviation. To learn about the nonlocal mathematics relevant for this study, participants engaged in a 90-minute Unbiased Estimator 
This is an author-produced, peer-reviewed version of this article. The final, definitive version of this document can be found online at Research in Mathematics Education, published by Routledge. Copyright restrictions may apply. doi: 10.1080/14794802.2017.1333918

Lesson (UEL). The purpose of the UEL intervention was to develop the participants' understanding of unbiased estimators in relation to the variance and standard deviation statistics. In particular, it intended to help participants connect the two common formulas for standard deviation to the inferential notion of estimators, linking their mathematical understandings about standard deviation to this broader statistical issue.

The UEL was divided into three main parts. First, the notions of estimators, bias, and unbiased estimator were developed through an activity involving estimating the number of tanks owned by Germans during World War II (see Peck, Gould, Miller \& Zbiek (2013) for a complete description). In this activity, students were given seven serial numbers for German tanks - considered to be a random sample from the population of all German tanks which were numbered starting at 1 when produced - and asked to provide at least two methods for using the sample of serial numbers to determine the actual number of tanks. Students were told that the actual number of tanks was the parameter of interest; their computation(s) from the random sample of serial numbers were the statistic(s) for estimating the number of tanks. After being told the actual parameter value, students evaluated which estimator was best. The purpose of the tank activity was to emphasize the inferential nature of a statistic - a means for estimating a population parameter. Second, proofs that the sample mean is an unbiased estimator of the population mean and, most pertinent to this study, that the sample variance is an unbiased estimator of the population variance were presented (e.g., Ramachandran \& Tsokos, 2009, p. 248). The second proof used expected values to demonstrate that the uncorrected sample variance formula (dividing by $n$ ) produces a biased estimate of the population parameter while a correction to divide by $n-1$ produces an unbiased estimate. Third, a dynamic demonstration (depicted in Figure 2) was used to empirically demonstrate that division by $n$ in the sample standard deviation formula creates a more biased estimator of the population standard deviation while division by $n-1$ creates a less biased one. It showed that when repeated samples of the same size are drawn from the population, the mean (expected) value of the uncorrected sample standard deviation statistic is further from the actual value of the population parameter than is the corrected sample standard deviation statistic. At the close of the lesson, the class discussed how the notion of statistical inference relates to the various formulas for standard deviation. The researcher at each of the four sites led the UEL for the participants at that site.

[Insert Figure 2: Fathom simulation of uncorrected and corrected sample standard deviation statistics]

\section{Pre- and Post-Data Collection and Data Analysis}

Data were collected before the teaching of the UEL (pre-data), as well as afterwards (post-data). We elaborate on the data collected and the analyses, particularly as they pertain to the research questions and framework. For the analyses, the researchers divided into two teams of two, with one team focused on content knowledge and the other on the lesson plans. Members within each team considered the data individually at first and then collaboratively to achieve consensus.

Pre-UEL Lesson Plan. Prior to the UEL, the participants designed and submitted a lesson plan whose objective was to teach standard deviation to secondary students. Specifically, the directions provided to the participants were:

"Write a lesson plan for which the objective is to have students understand standard deviation. The lesson plan can be contained within a regular class, a block period, or run over a few day period. Your primary goal is to describe in detail the key ideas that you would develop during this period, and the key tasks/activities/assignments that you would include to make sure students develop a solid understanding about standard deviation.”

For this paper, we report on the results of the analysis of these lessons for their levels of cognitive demand and student activity regarding how they intended to address division by $n-1$ in the sample standard deviation statistic. We focused on this aspect of their lesson plans because it is most relevant to the research question and this is the primary place where secondary instruction about standard deviation might allude to inferential - not just descriptive - facets. Two researchers analyzed each of the lessons specifically around if and how they planned to address this idea, and used the method of constant comparison (e.g., Strauss \& Corbin, 1990) to characterize themes across the participants indicating the primary ways they planned to deal with this in their lesson plans.

Content Knowledge Assessment. As mentioned, a content knowledge assessment was designed by the research team and administered pre-UEL in order to select participants. Only three of the items were relevant for the present study; these are presented in Table 1. The same content knowledge assessment was also administered at the beginning of the 
This is an author-produced, peer-reviewed version of this article. The final, definitive version of this document can be found online at Research in Mathematics Education, published by Routledge. Copyright restrictions may apply. doi: 10.1080/14794802.2017.1333918

post-UEL interview (described in further detail below). Although identical, we do not utilize these as a source of comparison: our analysis of the post-UEL content knowledge assessments provided a sense of participants' inferential notions of standard deviation, which were explicitly introduced in the UEL, meaning that analysis of the pre-UEL content assessments for notions of inference would not have been productive.

Overall, the items provided a sense of participants' knowledge about standard deviation. The Pizza Delivery item was more general in nature, providing an overall sense of the participant's meanings for standard deviation, which may or may not include inferential notions. The Formula Explanation task provided a sense of whether participants could explain the reasoning behind the sample standard deviation formula being calculated the way that it is - including an opportunity to explain the division by " $n-1$ ". The President Age item, which presented every American president's age at inauguration, assessed whether participants attended to issues of population and sample in their consideration of standard deviation. Responses to each of the three questions can provide a general idea about participants' understanding of standard deviation, but can also provide insight into teachers' inferential sense about statistics.

[Insert Table 1: Selected items from the standard deviation content knowledge assessment]

In terms of analysis, the post-UEL content knowledge assessment was used to inform the degree to which each participant's responses were indicative of an inferential knowledge of estimators. We coded participants' responses in terms of the degree to which "estimator knowledge" was present in their responses. On each of the assessment items there were opportunities for the participant to indicate some sense about their understanding of the (corrected) sample standard deviation statistic. On the Pizza Delivery item, this meant participants included an interpretation of the standard deviation statistic in relation to the population of all pizza delivery times; on the Formula Explanation item, particularly in response to "This sum is divided by $n-1$ to...," this meant a specific indication that dividing by $n-1$ (rather than $n$ which is the sample average) gives a better estimate of the population parameter of standard deviation. For the President Age item, in addition to selecting "choice c", researchers looked for evidence of the participant providing an account for why there was no need in this situation for the typical correction from a sample (i.e., using $n-1)$ as it relates to inference. The analysis of the post-UEL content knowledge assessment resulted in classification of the participants into levels of sophistication regarding the visibility of their understanding of the inferential nature of standard deviation in their responses.

Post-UEL Interview. A semi-structured, individual Post-UEL interview was conducted with each participant by a researcher (who was not their instructor) within one week of their participation in the UEL. First, they completed the post-UEL content knowledge assessment. Then they were provided a copy of their standard deviation lesson plan and asked to talk through it, highlighting the important ideas and tasks in the lesson. Next, they were asked, "If you were writing a lesson plan [on standard deviation] from scratch today, would it look any different? If so, how and why? If not, why not?” Their replies determined how (if at all) the participants' planned instruction on standard deviation might change after the UEL. Follow-up questions were asked to fully develop ideas they shared. The interviewer, if it had not come up previously, was also directed to ask: "How does your lesson address standard deviation as an estimator of the population parameter?" Finally, the interview ended by asking "How would you respond to a student who asks 'Why does the standard deviation formula divide by $n-1$ ?' Explain why you are responding in this way.” The interviews were audio-recorded and then transcribed.

Analysis was conducted by both pairs of researchers on the post-UEL interview data. First, the last two interview questions allude to knowledge of estimators. Hence, participant's responses to these two questions were analyzed by the content assessment team as an additional source of data to help confirm and refine the assessment of their estimator knowledge. The second phase of analysis by the lesson plan team examined the participants' responses regarding both how their lessons would change, and particularly how they would address division by $n-1$ in the calculation of standard deviation. All the responses to the interview questions were analyzed using the method of constant comparison (e.g., Strauss \& Corbin, 1990).

Importantly, once the initial analyses of the content assessments, lesson plans, and interviews were done, the researchers explored themes within and across cases that were especially pertinent to the research questions. Namely, in what ways the teachers planned to address division by $n-1$ in their lessons, and whether there was an indication from the data that the degree to which participants engaged their students in thinking about the inferential notion of division by $n-1$ versus $n$ was in fact related to their own sense of statistics as estimators, based on the visibility of this idea in their responses. 
This is an author-produced, peer-reviewed version of this article. The final, definitive version of this document can be found online at Research in Mathematics Education, published by Routledge. Copyright restrictions may apply. doi: 10.1080/14794802.2017.1333918

\section{Findings}

The findings are organized according to their alignment with the research questions. First, we consider participants' pre-UEL lesson plans and post-UEL interview responses, focusing on how they addressed the issue of division by $n$ 1 in the standard deviation statistic in their proposed lessons. This provides a comparison of planned teaching practices that addresses the first research question: In what ways do teachers' plan for teaching standard deviation, particularly for addressing the issue of division by $n-1$ ? Next, we consider instructional changes in relation to findings about participants' (nonlocal) knowledge of estimators, based on its visibility in their responses. In each of these sections, we portray the findings with illustrative examples from the data. This answers the second research question: What role does understanding statistics as estimators of population parameters play in their plans? Additionally, we include data from four characteristic participants (referenced by pseudonyms - Tom, Dylan, Feliz, Ellen, different from the numerical identifications that identify other participants) in each of the findings' sections as well as the discussion section to help illustrate our findings.

\section{Pre- and Post-UEL Instructional Approaches for Addressing Division by n-1}

In this section, we present the categories identified from the data as a response to the first research question, which describe how the participants' lessons addressed the issue of division by $n-1$ in the formula for the sample standard deviation statistic. Five classifications resulted from analyzing the pre-UEL lessons. In the post-UEL lessons, the same five descriptions were applicable and two were added that were present exclusively in the post-UEL lesson plans. These seven categories differed regarding their levels of student activity and cognitive demand.

First, we present descriptions of the seven categories (in order from lower levels of student activity and cognitive demand to higher levels) along with illustrative examples from either pre- or post-UEL lessons. Next, figures that summarize the lesson plan data across all participants and help depict specific changes in the instructional approaches for each of the individual participants from pre- to post-UEL are shown and discussed.

Does Not Address. Some participants did not address the issue of $n-1$ or the notion of an estimator at all in their lessons; these examples came exclusively from the pre-UEL data. For example, one participant (B03) only presented the population standard deviation formula (dividing by $n$ ), and never clarified that this was only applicable to population data. Two other participants (T01, Dylan) elected not to introduce students to any formulas at all - their lessons plans relied on students using the calculator to compute standard deviation. This is not to indicate that their overall lessons were poor; rather, it reveals that these participants opted not to address the issue of division by $n-1$ at all in their (pre-UEL) lesson plans.

Procedural Explanation. One of the most common approaches in the pre-UEL lessons was a very literal and procedural explanation of the standard deviation formula. Although these lessons provided a very procedural approach to explaining the entire formula(s), in this context we are indicating that they, in fact, explicitly distinguished the sample and population formulas but in a very procedural way. Sometimes they included both formulas, at other times, only one, but the gist of their explanation was: this is the formula for the standard deviation of a sample, and this is the formula for the standard deviation of a population. No further discussion was given to why these formulas might be different - they only attended to ways to determine which formula to use:

"If comparing the number of each color with some percentage given by the candy manufacturer for all the candy made, the students would divide by $(n-1)$ rather than $n$, as we are finding a sample standard deviation, not a population deviation.” (Feliz, pre-UEL, italics added)

"Clarify to the students that this equation is for a population data set. Since we are working with the entire class, our population is the students of the class. If we wanted to have our population be the entire student body at the school and had only this data, it would be a sample population data set, which requires a different equation." (Tom, pre-UEL, italics added)

In addition to these examples, some participant's lessons had students compute the sample and population standard deviation formulas for the same data set (e.g., "Use the values: 6.9, 8.7, 7.6, 4.8, 9.0. What is the sample standard deviation of the values? What is the population standard deviation of those values?" (D01, pre-UEL)). That is, they distinguished between the formulas for students, but there was no sense as determining which one would be valid in a particular context - the formulas just gave different values. 
This is an author-produced, peer-reviewed version of this article. The final, definitive version of this document can be found online at Research in Mathematics Education, published by Routledge. Copyright restrictions may apply. doi: 10.1080/14794802.2017.1333918

Procedural Explanation with Conceptual Inadequacies. Whereas the previous group pointed out the differences in the formulas for population and sample standard deviation without explanation, participants' responses in this category attempted to explain why the formulas were different. However, responses in this category had explanations that were not related to a sense of estimation, and the explanations were, in fact, conceptually inadequate. For example, one mentioned, "Divide by $N$ (or $N$-1 if the $N$ is small...)" (B02, pre-UEL), which indicates that the choice of the divisor in the calculation of standard deviation depends on the size the sample (or population); another suggested it had to do with "accounting for outliers in the sample" (B01, post-UEL). Three participants (E41, Ellen, Tom) recognized that division by a smaller number would result in a slightly larger value for the sample standard deviation, but either provided inaccurate explanations as for why the slightly larger value occurs, or no explanation at all.

“There are two ways to calculate standard deviation depending on whether your data is from a whole population or from a sample... So, if we have data from the entire population, [this is the formula]... It is just a little different if we are only looking at a sample. If we have a sample, [this is the formula]... Briefly discuss that the higher standard deviation for the sample than the population means that the data points were more similar to the mean in the population than in the sample." (Ellen, pre-UEL, italics added)

"I would basically say that we have to subtract one from our population, from our sample size um to be, to account for the fact that this isn't our entire data set. Um so we're bringing our standard deviation up a little bit by subtracting one from our sample size" (Tom, post-UEL interview, italics added)

Conceptual Explanation. In her pre-UEL lesson, Feliz provided a procedural explanation to distinguish between the two formulas for standard deviation; in the post-UEL interviews, she explained:

"I might go into a little more detail about when you use $n$ and when you use $n$-1. I probably wouldn't go into the whole proof... but when [we] don't know the whole population [we] kind of need a little extra wiggle room....Um when you divide by a smaller number, you get a slightly bigger answer. Subtract by one so our answer will be ever slightly bigger so we know [the estimate] is not as accurate as measuring every single one.” (Feliz, post-UEL, italics added)

In this example (and others in this category), we see explanations that begin to address the conceptual idea regarding the difference in the two formulas, and that are at least partially related to issues about estimation. However, in these examples (compared with those in the next category), the primary emphasis is not about estimation per se but about something else; in Feliz's case, of including a little extra variability in the computation of the statistic since we do not have data from the entire population.

Estimator explanation. Responses in this category addressed issues of estimation explicitly when explaining division by $n-1$ in the formula for the standard deviation statistic, with the explanation coming from the teacher. One participant, E22, was explicit about this in both the pre- and post-UEL data. Her pre-UEL lesson included: "s is the sample standard deviation which is an estimate of the unknown population standard deviation. We divide the sum of squares by 1 less than the sample size to account for error in estimation from the sample standard deviation (called the degrees of freedom)." Her post-UEL interview reiterated this idea. Other participants gave similar explanations. Ellen, who in the pre-UEL lesson plan had attempted, albeit unsuccessfully, to give a reason for why the formulas were different, explained this in relation to estimation in the post-UEL interview:

"I think [the UEL] kind of cleared some things for me in my head... that you divided by $n-1$ instead of $n$, and again that was something I didn’t understand why we are doing that and it just turns out that it just works out better that way so we do it... we are just trying to use whatever is working best [as an estimate].” (Ellen, post-UEL, italics added)

Simulation-Based Estimator Explanation. For these participants, rather than simply providing a verbal explanation, they planned also to incorporate a simulation-based visual for students in order to demonstrate that using $n-1$ provided a better estimate of the population parameter than division by $n$. This was mostly attributed to the simulation-based demonstration that was part of the UEL. One participant, T01, who had previously not addressed any sense of estimation in her pre-UEL lesson, discussed using such a demonstration to help students follow the notion of estimation: "I think I'd be able to explain [standard deviation], I guess, a little bit better... We wound up doing a simulation in [the UEL] which I think would be really nice to use to show students... it really gives us clarification as to why its $n-1$ and not $n$ " (T01, post-UEL, italics added). Another participant, D01, who had previously given a procedural explanation in the pre-UEL lesson plans, discussed the use of a (single) simulated visual from a sample: 
This is an author-produced, peer-reviewed version of this article. The final, definitive version of this document can be found online at Research in Mathematics Education, published by Routledge. Copyright restrictions may apply. doi: 10.1080/14794802.2017.1333918

“Obviously, this isn’t the only estimate they will do...I know that I wouldn’t be completely happy with the lesson... you know, the 'whys' instead of just the 'hows'. Why do we subtract these values? What does it do for us? I feel like they would need some kind of visual as well in the discussion between the population and the sample and the $n$ and the $n-1$ to help them understand that... We could graph [the population data] in a line graph and look at those and see where the data lies and [then] look at if we just took a [sample] would [using] the average [that is, division by $n$ ] be ok.” (D01, post-UEL, italics added)

Discovery-Based Estimator Activity. A few participants included student activities in their lessons that engaged students in doing mathematics around this idea of estimation (rather than an explanation or a simulation). One participant, Dylan, who had not addressed any sense of estimation in her pre-UEL lesson (having elected to use a calculator feature instead) discussed having the class do an activity:

"I'm also wondering if I could do something with a sample and the whole class. The whole class could work as my population and then do a smaller portion that could work as a sample and we could look at the difference between the two, and how our [sample] standard deviation gets closer [to the true standard deviation] when we use $n-1$ as opposed to if we had used $n$ for the sample.” (Dylan, post-UEL, italics added)

Another student, T03, who had planned for something similar in the Pre-UEL lesson, considered using the following activity:

"Consider a data set with $N=3$ : $\{0,2,4\}$. Make a table with all possible samples of size $n=2$, find their sample means and sample variances. Then calculate the mean of all s2s and compare this to $\sigma 2$. Repeat this process [but divide by $n$ ]. Try to convince me $n-1$ is the better divisor.” (T03, postUEL)

Thus, a few teachers planned to address the issue of division by $n-1$ versus $n$ through a discovery-based activity where students would come to understand the distinction between the two formulas through the lens of estimation and inference.

Summary. Lessons in these seven categories notably differ regarding the level of activity and cognitive demand for the students. For example, a verbal explanation places the student in a passive role with nearly all of the activity on the teacher, whereas a dynamic visual alongside a verbal explanation requires students to be more active in coordinating the two presentations. A discovery-based task places students at the center of activity. Similarly, in terms of cognitive effort being demanded of students, there are analogous increases when moving from a procedural explanation to a conceptual one, etc., which we have aligned to Stein et al.'s (2009) cognitive demand levels. Thus, we have provided a table of these differing instructional approaches as an ordinal classification, where moving up indicates more cognitively demanding and increasingly student-centered approaches.

[Insert Table 2: Instructional approaches for Pre- and Post-UEL lessons about division by $n-1$ ]

As noted, many of the examples of the lower-ranking responses came from the pre-UEL lessons, and the higherranking responses from the post-UEL interviews. Across all the data, we consider the primary distinction made by Stein et al. (2009) between lower-level (memorization and procedures without connections) and higher-level (procedures with connections and doing mathematics) tasks: 88\% (14/16) of participants addressed the distinction between $n$ and $n-1$ in a lower-level way in the Pre-UEL lessons, but after the UEL, 57\% (8/14) ${ }^{1}$ discussed engaging students in higher-level tasks. In terms of the cognitive demand and student activity planned for around the particular issue of dealing with division by $n-1$, we see an overall shift from lower-level types of engagement for students to higher-levels. This overall trend is evident in Figure 3 - a two-way plot of pre- and post-UEL instructional approaches. Notably, those who had higher instructional approaches in the pre-UEL lessons remained high in their post-UEL interview responses; and of the participants whose pre-UEL lesson plans evidenced lower instructional approaches, half moved to higher approaches in the post-UEL interviews. Hence, there is evidence that a sizable number of participants changed their instructional approaches about standard deviation to incorporate meaningful notions of estimation and inference into their planned explanations and activities following the UEL.

\footnotetext{
${ }^{1}$ Two participants did not respond to the interview query relevant for the Post-interview, and thus were removed from the post-UEL analysis.
} 
This is an author-produced, peer-reviewed version of this article. The final, definitive version of this document can be found online at Research in Mathematics Education, published by Routledge. Copyright restrictions may apply. doi: 10.1080/14794802.2017.1333918

\section{Estimator Knowledge}

Teachers' knowledge of estimators is considered nonlocal knowledge of mathematics for the teaching of standard deviation at the secondary level. From the post-UEL content assessment and interview, a sense of participants' knowledge of estimators was acquired through the degree of visibility of inferential notions present in their responses. We characterize each participant according to the visibility - low, medium, high - of this inferential notion of statistics as estimators within their responses.

Low-Visibility. Participants in this category (3/16) gave almost no indication in their responses about standard deviation as an estimator. That is not to say that they knew nothing about standard deviation, but rather that their postUEL responses regarding standard deviation and teaching did not incorporate inferential notions of estimation deemed low-visibility. These participants discussed standard deviation primarily in terms of its descriptive nature. For example, "A standard deviation of eight point one minutes tells me that you have roughly most of your data is between about twenty-eight minutes and about forty-four minutes...” (Tom, post-UEL (pizza delivery), italics added). In addition, these participants did not distinguish meaningfully between a population and a sample when prompted on any of the other assessment questions.

In their explanations of division by $n-1$ in the sample standard deviation statistic (in the Formula Explanation item question and during the interviews), they attempted to provide an explanation but it ended up being inadequate or nonsensical. For example, Tom explained, “dividing by $n-1$ gives us our average of the minutes squared” and "we have to subtract one from our population, from our sample size um to be, to account for the fact that this isn't our entire data set. Um so we're bringing our standard deviation up a little bit by subtracting one from our sample size” (italics added). In Tom's responses, we see a focus on the division by $n-1$ as a "pseudo-average" and in increasing the value of standard deviation a little bit, but none of the comments suggest that it has to do with being a better estimate of the population value. Despite talking about what the effect on the value of the standard deviation calculation would be (a slight increase), there is no hint at its inferential nature in his responses. Another participant, B02, stated, "and $n$-1 was Bessel's correction to adjust for the fact that we, oh well, you know, I don't know why Bessel's correction works but I know that we use it” (italics added). Again, B02's response does not provide an indication about estimation; it has something to do with a need to adjust something, for some reason, but the inferential notions about estimation were minimal in these responses.

Medium-Visibility. Participants with a medium-visibility of estimator knowledge (8/16) in their responses provided at least some indication that sample standard deviation was serving as an estimator for the population parameter. These participants never articulated this idea entirely, but it was at times visible in their content knowledge assessment answers and interview responses. Replies to the Pizza Delivery item were typically ambiguous; that is, it was unclear whether the claims were just about the sample, or about a broader population. For example, "Not knowing if it was normally distributed or not, I figured you could say for advertising or looking at the Better Business Bureau or something you could say that most pizzas would be delivered between 28 and 44 minutes” (Feliz, post-UEL, italics added).

In response to division by $n-1$, these participants attended explicitly to issues of population and sample, but they were not necessarily explicit with the notion of estimation. For example, Feliz stated, "you can divide by $n-1$ to get an average... but [it's] because it is not the entire population it evens it out a little bit by dividing by n-1" and "I'm not $100 \%$ sure what the actual population mean is. So I know I don't know what the actual standard deviation will be so I need a little bit more room to measure away from this mean that I'm not sure about. So I want just a little, little extra room on each side" (italics added). Other participants in the medium-visibility category had similar responses: there was an indication they considered standard deviation in terms of an (unknown) population parameter, explicitly distinguishing between sample and population, but the relationship appeared to be more about uncertainty in samples, and less explicit about inferential notions of estimation and expectation.

High-Visibility. Lastly, some participants (5/16) - including both Ellen and Dylan - responded in ways that had a high-visibility of estimator knowledge, explicitly capturing the estimator sense of standard deviation. Similar to the medium-visibility category, their language on the Pizza Delivery task, while at times ambiguous, potentially allowed for extrapolation to a broader population (e.g., "Delivery times will generally vary by 8.1 minutes (shorter or longer) than the average” (Ellen, italics added)). 
This is an author-produced, peer-reviewed version of this article. The final, definitive version of this document can be found online at Research in Mathematics Education, published by Routledge. Copyright restrictions may apply. doi: 10.1080/14794802.2017.1333918

However, in addition to this, we saw both explicit attention to sample versus population as well as explicit links to estimation from participants in this category. For example, Ellen explained, "Because this is every American president and not just a sample, we need to find the standard deviation for a population" and "we are just trying to use whatever is working best [as an estimate], and so because it's working best that's... why we should use it" (italics added). Similarly, T03 mentioned, "but the reason it's minus one instead of just $n$ (sighs) is also complicated to explain. But um (pause) it uh it accounts for the difference of using a sample size versus the entire population" and "an unbiased estimator is a method you can use that, that will allow you to kind of extrapolate from a sample to try to get as close as you can to the population" (italics added). In these responses, the visibility of inferential notions is much higher, and there is a clearer indication that these participants have a solid grasp on the inferential nature of the standard deviation statistic, differentiating between sample and population as well as linking the two via notions of estimation and inference.

\section{Exploring the Relationship Between Nonlocal Knowledge and Instructional Approach}

To answer our second research question, we were particularly interested in whether there appeared to be a meaningful relationship between the visibility of a teacher's nonlocal knowledge of statistics as estimators and their instructional approaches for addressing division by $n-1$ in the sample standard deviation formula. Figure 3 provides a sense of the potential relationship based on the data from this exploratory study, which displays each participant's shift from preto post-UEL instructional approaches, with a third categorical variable overlaid: the visibility of participants' "estimator knowledge". From this figure, we highlight two things. The first is the overall shift from lower-level types of engagement to higher levels of student engagement, particularly for those with lower-levels of engagement in their pre-lesson plans. The second is that the visibility of participants' understanding of standard deviation as an inferential estimator in their responses may be related to some of the change: namely, participants with more visible expressions of estimator knowledge were those who shifted to higher-ranked instructional approaches after the UEL. For those whose pre-UEL lessons had lower-ranked instructional approaches, the ones that shifted to higher-ranked instructional approaches (which indicated using more active and cognitively demanding tasks to address the issue of $n$ versus $n-1$ in standard deviation) were those with more visible knowledge of estimators. Both (2/2) of those with high-visibility and half (4/7) of those with medium-visibility shifted their instructional approach; none (0/3) of those with lowvisibility did. Indeed, there was an overall positive relationship between the visibility of teachers' post-UEL estimator knowledge and the post-UEL instructional approach for addressing division by $n$ versus $n-1$.

[Insert Figure 3: Shift from pre- to post-UEL instructional approaches]

\section{Discussion and Implications}

Secondary mathematics teachers are responsible for teaching students about standard deviation per current curriculum standards (e.g., Brazil- Ministério da Educação, 2006; South Africa-Department of Education, 2002; USA-CCSSI, 2010). The standard deviation statistic is primarily introduced in secondary mathematics as a measure of typical variation or spread of data. Within this context, standard deviation is used in a descriptive role - describing a feature (spread) of the dataset's distribution. Yet only considering sample standard deviation as descriptive for a dataset provides a sense of cognitive conflict regarding why the formula includes an "averaging" step using division by $n-1$ instead of $n$. Participating teachers expressed this conflict: "this is one of those times when math is kinda silly" (E41). In a descriptive context, one could potentially get around this issue by describing it as a kind of "pseudo-average," something similar to the true "average" deviation. Indeed, division by $n$ and $n-1$ yield very similar numbers, often within hundredths of each other - so much so that some argue for using the friendlier population standard deviation in most cases (e.g., Speed, 2013). But, particularly in a classroom that emphasizes reasoning and sense-making about mathematics, a commonly shared goal in reform efforts (CCSSI, 2010; NCTM, 2014), the question "why?" still lingers. In such classrooms, drawing on nonlocal inferential notions in statistics - outside the local context of descriptive measures - becomes important for teaching.

This study explored how such nonlocal content knowledge interacts with teachers' planned practices for teaching standard deviation. The variety of different approaches mentioned by participants for addressing division by $n-1$ in the standard deviation formula - ranging from not addressing it at all to discovery-based activities for students - is of interest itself. From it we see a relatively broad range of instructional approaches for teaching about statistics that is 
This is an author-produced, peer-reviewed version of this article. The final, definitive version of this document can be found online at Research in Mathematics Education, published by Routledge. Copyright restrictions may apply. doi: 10.1080/14794802.2017.1333918

noteworthy. Additionally, we find of particular interest the exploration of the relationship that teachers' increased sense of the inferential notion of standard deviation as an estimator (estimator knowledge) was related to higher levels of student activity and cognitive demand in teachers' planned practices (Figure 3).

Along with these overall results, we included data from four participants - Tom, Dylan, Feliz, and Ellen - throughout the findings. We briefly summarize the data from these four participants to illuminate additional nuances regarding our findings. Tom submitted a pre-UEL lesson plan that distinguished between sample and population, but only in a procedural way. That is, the explanation was limited to a procedural distinction between sample and population, which told students which formula to use; however, there was no attempt to make sense of why the formulas were different. This primarily procedural approach persisted, even after the UEL. This makes sense in relation to the observation that the visibility of inferential notions of estimation in his responses about standard deviation was minimal, even after the UEL. Similar to Tom, Feliz initially had a very procedural approach on the pre-UEL lesson plan; however, the postUEL interviews indicated a change in this regard. Namely, Feliz changed her lesson to include some explanation as to why the formulas might differ - which she related to the conceptual notion of needing "a little extra wiggle room" in the calculation (division by $n-1$ produces a slightly larger standard deviation value) to account for a sample not being the full population. We also saw movement beyond just procedural instruction in her lesson plan, which, postUEL, provided some sense of meaning for the formulas in relation to estimation. Correspondingly, her responses about standard deviation after the UEL included a medium visibility of estimator knowledge.

Ellen and Dylan were also on the lower-end of the pre-UEL instructional approaches (albeit for different reasons) but post-UEL had shifted to higher instructional approaches. They also both demonstrated a more thorough integration of statistics as estimators in their responses about standard deviation post-UEL. Ellen was similar to Tom and Feliz in that the shift was between explanatory approaches: her pre-UEL approach was mostly procedural and the attempt to provide an understanding as to why was conceptually inaccurate, but post-UEL the explanation given had conceptual ideas that were explicit about the notion of estimation - an estimator explanation. Dylan, however, was different. In the pre-UEL instruction, Dylan did not address the issue of formulas, opting instead to have her students use a calculator button to compute standard deviation. Yet although she did not intend for her students to grapple with division by $n-1$, the lesson overall had a lot of student activity and was conceptual in nature, requiring students to come up with a meaning for the standard deviation value in terms of its descriptive nature. Dylan's post-UEL interview indicated a desire to really have her students grapple with the formulas, which was a change from her pre-UEL lesson; but, similar to her pre-UEL focus on student activity and conceptual understanding, she designed a very studentcentered and cognitively demanding activity that had students explore the issue of division by $n-1$ by computing the standard deviation value for the whole class, and then using samples of the class to discuss which formula was a better estimator of the whole-class parameter.

We see these trends within the data as important; however, we also attend to a few particulars. First, we note that the increased levels of student activity and cognitive demand (higher instructional approaches) that were related to the nonlocal content knowledge were only in relation to how teachers planned to address the distinction between $n$ and $n$ 1 in their lesson - not necessarily their entire lessons about standard deviation. The case of Dylan illustrates this idea: she would not have changed her initial instructional approach for standard deviation, but it would be further supported by additional investigation into the issue of division by $n-1$. This is notable, as it suggests that such nonlocal content knowledge may interact only with relatively smaller parts of planned practices. Even for those whose responses had a high-visibility of inference and estimation regarding statistics, this knowledge did not appear to fundamentally alter the entire direction of their lesson; they felt comfortable with nearly all of their planned lesson about standard deviation except the particular nuance of dealing with division by $n$ compared to $n-1$. For this one facet, their post-UEL plans included a more intentional exploration of the issue - not something just to be glossed over procedurally.

The second trend of note is that these instructional changes worked in conjunction to and were consistent with their overall lesson plans. Without jeopardizing the integrity of the idea of parameter estimators, teachers with more visible expressions of inference seemed more able to convey its essence - whether through explanation, simulation, or activity - in ways consistent with their overall pedagogical approach. Three of the cases (Tom, Feliz, Ellen), for example, demonstrated shifts in their planned instruction about division by $n-1$, relying, essentially on teacher explanations. Granted, there is a difference in the cognitive demand of a procedural explanation and one that requires making sense of why, or in coordinating both auditory and visual representations, but in these cases the instructional approach was still primarily explanatory. The fourth case, Dylan, in contrast, discussed a more student-centered activity. This, in fact, was also aligned with her pre-UEL lesson approach, which was similarly student-centered, but never addressed 
This is an author-produced, peer-reviewed version of this article. The final, definitive version of this document can be found online at Research in Mathematics Education, published by Routledge. Copyright restrictions may apply. doi: 10.1080/14794802.2017.1333918

the particular issue of division by $n$ or $n-1$ in the formulas. Thus, we see some sense of a broader consistent pedagogical approach, too, across these four cases, in both their overall lessons and their approaches for addressing the issue of division by $n-1$. We cannot completely tease out some of these potentially conflating issues from the given data. However, the data do support the sense that those whose responses indicated a better understanding of statistics as estimators incorporated instructional approaches that were more cognitively demanding and involved more student activity. Rather than glossing over the issue, these teachers felt more comfortable releasing some degree of cognitive demand and/or control in their lesson plans over to students.

Lastly, we discuss a few limitations of this study. First, the small number of participants $(n=16)$ in this exploratory study limits the generalizability of the findings; however, the study generates interesting hypotheses that should be investigated further. Our data suggest that knowledge of nonlocal mathematical content appears to play a role in influencing the teaching of specific local content, in particular fostering instruction that allows for more reasoning and sense-making. Future research could look more deeply at the role and influence that knowledge of nonlocal mathematical content might have on specific teaching practices, as well as investigate the potential impact not just on planned practices, but also teachers' enacted practices. Research indicates that teachers who are uncomfortable with content often lack confidence in teaching, and tend to omit content entirely or enact the lesson plans in a superficial, often procedural, manner (e.g., Brown \& Borko, 1992) - what role might knowledge of nonlocal content (and not just local content) play in such teaching practices? In preservice teacher education, there are recommendations to learn about such topics (see ASA's (2015) report for current recommendations), yet there is scant research evidence to empirically establish the benefits (or potential drawbacks) of such knowledge for teachers. What we have presented in this study supports such recommendations, but is just a start.

Second, is the UEL itself. Although the UEL was designed to help address the issue of interest in this study explicitly, the particular implementation of the UEL may have been a factor in the results from this study. First of all, despite all sixteen participants engaging in the same UEL, relatively few seemed to display and articulate a significant conceptual advance in their inferential understanding of estimator. This is likely related to the relative brevity of the UEL (90 minutes), but also potentially speaks to the difficulty of helping teachers acquire a deep understanding of formulas for standard deviation in terms estimating a population parameter. Regardless, it is unclear the role that the UEL activities played in either helping or hindering participants' development. In addition, the teachers seemed to value the use of a dynamic demonstration for its help in illustrating and clarifying the issue; indeed, some participants mentioned using this demonstration with their own students. Such a result may or may not be desirable more generally. However, in this study, although the teachers found the informal explanations and approaches, such as the simulation demonstration in the UEL, particularly compelling and applicable for their own teaching, they themselves asked for more rigorous justification during the UEL. For example, the participants questioned why division by $n$ - 1 (instead of, say, $n$-2) would produce an "ideal" estimator, at least for variance ${ }^{\mathrm{ii}}$, which required more formal proof (e.g., Ramachandran \& Tsokos, 2009, p. 248). This seems to be a function of how they differentiated between the nonlocal knowledge they themselves engaged in, which included more rigorous proof, and what they identified as appropriate for secondary students. Thus, when exploring nonlocal content with teachers, we regard leveraging both formal and informal approaches in conjunction with one another as productive, because the teachers seem to have benefitted from both aspects.

\section{Conclusion}

In sum, we see this work as contributing toward an understanding of the potential role that nonlocal content knowledge can play in the teaching of more elementary ideas, as was evident in the different approaches for teaching about division by $n-1$ in the standard deviation statistic. From the participants in this study, there is an indication that such knowledge - in this case an inferential (not descriptive) understanding of the standard deviation statistic - can play a role in informing teachers' planned instructional approaches in terms of levels of student activity and cognitive demand in their instruction. Though we focused on a relatively small portion of the entire lesson, and there may be other general pedagogical tendencies at work, we see this role as an important one, particularly when a primary aim of instruction is fostering student reasoning and sense-making in the classroom. The connections between standard deviation, variance, bias, and estimators are nuanced, but the broader idea that statistics are computed to have inferential meanings, and not just descriptive ones, is critical. Such key understandings must guide school mathematics instruction. Otherwise we, as educators, risk providing students with smoke screens as a substitute for real reasoning and understanding. 
This is an author-produced, peer-reviewed version of this article. The final, definitive version of this document can be found online at Research in Mathematics Education, published by Routledge. Copyright restrictions may apply. doi: 10.1080/14794802.2017.1333918

\footnotetext{
'We say "potentially" different formulas because, for a normal distribution, the formulas for the maximum likelihood estimator of standard deviation from a sample and the population standard deviation are the same.

${ }^{\text {ii }}$ In fact, it makes sense to explore other possibilities at times: division by $n-1.5$ in a normal distribution provides an estimate for standard deviation with even less bias than $n-1$ (e.g., Bloch, 1968; Brugger, 1969)
}

\section{References}

American Statistical Association (ASA). (2015). Statistical education of teachers. Alexandria, VA: Author.

Ball, D. L., Thames, M. H. \& Phelps, G. (2008). Content knowledge for teaching: What makes it special? Journal of Teacher Education, 59(5), 389-407.

Bolch, B. W. (1968). More on unbiased estimation of the standard deviation. The American Statistician, $22(3), 27$.

Brown, C., \& Borko, H. (1992). Becoming a mathematics teacher. In D. A. Grouws (Ed.), Handbook of Research on Mathematics Teaching and Learning (pp. 209-239). New York: Macmillan.

Brugger, R. M. (1969). A note on unbiased estimation of the standard deviation. The American Statistician, 23(4), 32.

CCSSI (2010). Common Core State Standards (Mathematics). Washington, D.C.: National Governors Association Center for Best Practices \& Council of Chief State School Officers.

Department of Education (2002). Revised National Curriculum Statement grades R-9, mathematics. Pretoria, South Africa: Author.

Ministério da Educação (2006). National curricular guidelines for secondary school: Nature sciences, mathematics, and their technologies. Brasilia, Brazil: Author.

Nathan, M.J. \& Petrosino, A. (2003). Expert blind spot among preservice teachers. American Educational Research Journal, 40(4), 905-928.

NCTM (2014). Principles to actions: Ensuring mathematical success for all. Reston, VA: Author.

Peck, R., Gould, R., Miller, S. \& Zbiek, R. M. (2013). Developing Essential Understanding of Statistics for Teaching Mathematics in Grades 9-12. Reston, VA: NCTM.

Ramachandran, K. M., \& Tsokos, C. P. (2009). Mathematical statistics with applications. Burlington, MA: Elsevier Academic Press.

Rowland, T., Huckstep, P. \& Thwaites, A. (2005). Elementary teachers' mathematics subject knowledge: the knowledge quartet and the case of Naomi. Journal of Mathematics Teacher Education, 8(3), 255-281.

Sánchez, E., da Silva, C. B. \& Coutinho, C. (2011). Teachers' understanding of variation. In C. Batanero, G. Burrill, \& C. Reading (Eds.), Teaching statistics in school mathematics-Challenges for teaching and teacher education. A Joint ICMI/IASE study: The 18th ICMI study (pp. 211-221). New York, NY: Springer.

Speed, T. (2013). Terrence's stuff: $n$ versus $n-1$. IMS Bulletin, 42(1), 15.

Stein, M. K., Smith, M. S., Henningsen, M. A., \& Silver, E. A. (2009). Implementing standards-based mathematics instruction: A casebook for professional development (2nd ed.). New York, NY: Teachers College Press.

Strauss, A., \& Corbin, J. (1990). Basics of qualitative research: Grounded theory procedures and techniques. Newbury Park, CA: Sage.

Wasserman, N. (2016a). Abstract algebra for algebra teaching: Influencing school mathematics instruction. Canadian Journal of Science Mathematics and Technology Education, 16(1), 28-47.

Wasserman, N. (2016b). Nonlocal mathematical knowledge for teaching. In Csíkos, C., Rausch, A., \& Szitányi, J. (Eds.), Proceedings of the 40th Conference of the International Group for the Psychology of Mathematics Education (PME) (Vol. 4, pp. 379-386). Szeged, Hungary: PME.

Wasserman, N., \& Stockton, J. (2013). Horizon content knowledge in the work of teaching: A focus on planning. For the Learning of Mathematics, 33(3), 20-22.

Wild, C. \& Pfannkuch, M. (1999). Statistical thinking in empirical enquiry. International Statistical Review, 67(3), 223-265.

Yin, R. K. (2014). Case study research: Design and methods (5th ed.). Thousand Oaks, CA: Sage.

Zazkis, R. \& Mamolo, A. (2011). Reconceptualizing knowledge at the mathematical horizon. For the Learning of Mathematics, 31(2), 8-13. 
This is an author-produced, peer-reviewed version of this article. The final, definitive version of this document can be found online at Research in Mathematics Education, published by Routledge. Copyright restrictions may apply. doi: 10.1080/14794802.2017.1333918

Table 1

Selected items from the standard deviation content knowledge assessment

Question

[Pizza Delivery] Anton's pizza delivery started collecting data about how long it takes them to deliver an order to a customer. For their collected data, the average time was 36.4 minutes and the standard deviation was 8.1 minutes.

Provide a written interpretation for the following value in this context.

A standard deviation of 8.1 minutes tells me that...

[Formula Explanation] The standard deviation of a sample is calculated using the following formula:

$s_{x}=\sqrt{\frac{\sum_{i=1}^{n}\left(x_{i}-\bar{x}\right)^{2}}{n-1}}$

? Complete the sentences below to explain each component of this calculation.

The difference of $x_{i}-x$ is done to... This

difference is squared to...

These squared values are summed to...

This sum is divided by $n-1$ to...

The square root of this quotient is done to...

[President Age] The following data lists every American president's age when taking office. The mean of this data is 54.6 years. How would you compute the typical variation or "deviation" for how far the typical president deviates from this average age?

$$
\begin{aligned}
& \text { 57, } 61,57,57,58,57,61,54,68,51,49,64,50,48,65,52,56,46,54,49,50,47,55,55,54,42, \\
& 51,56,55,51,54,51,60,62,43,55,56,61,52,69,64,46,54,47
\end{aligned}
$$

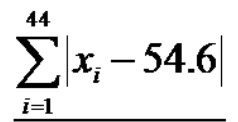
Circle one: a)
44

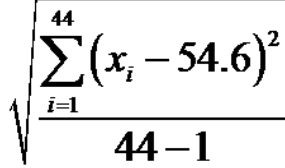
$\sqrt{\frac{\sum_{i=1}^{44}\left(x_{i}-54.6\right)^{2}}{44}}$

Explain your choice below...

Table 2

\begin{tabular}{|c|c|c|c|c|}
\hline $\begin{array}{l}\text { Instructional approaches for addressing } \\
\text { division by } n-1\end{array}$ & \multicolumn{2}{|c|}{$\begin{array}{l}\text { Level of Cognitive Demand } \\
\text { (i.e., Stein et al., 2009) }\end{array}$} & \multirow{2}{*}{\multicolumn{2}{|c|}{ Level of Student Activity }} \\
\hline Does not address & Memorization & \multirow{3}{*}{$\begin{array}{l}\text { Lower- } \\
\text { level }\end{array}$} & & \\
\hline Procedural explanation & \multirow{2}{*}{$\begin{array}{l}\text { Procedures } \\
\text { without } \\
\text { Connections }\end{array}$} & & \multirow{4}{*}{ Auditory (Listening) } & \multirow{5}{*}{ Passive } \\
\hline $\begin{array}{l}\text { Procedural explanation with conceptual } \\
\text { inadequacies }\end{array}$ & & & & \\
\hline Conceptual explanation & \multirow{3}{*}{$\begin{array}{l}\text { Procedures } \\
\text { with } \\
\text { Connections }\end{array}$} & \multirow{4}{*}{$\begin{array}{l}\text { Higher- } \\
\text { level }\end{array}$} & & \\
\hline Estimator explanation & & & & \\
\hline $\begin{array}{l}\text { Simulation-based estimator } \\
\text { explanation }\end{array}$ & & & $\begin{array}{l}\text { Coordinate Auditory } \\
\text { and Visual }\end{array}$ & \\
\hline Discovery-based estimator activity & $\begin{array}{l}\text { Doing } \\
\text { Mathematics }\end{array}$ & & Active & Active \\
\hline
\end{tabular}

Instructional approaches for Pre- and Post-UEL lessons about division by $n-1$ 
This is an author-produced, peer-reviewed version of this article. The final, definitive version of this document can be found online at Research

in Mathematics Education, published by Routledge. Copyright restrictions may apply. doi: 10.1080/14794802.2017.1333918

\section{List of Figures}

Figure 1. Research framework exploring relationship between knowledge of nonlocal mathematics and local teaching

Figure 2. Fathom simulation of uncorrected and corrected sample standard deviation statistics

Figure 3. Shift from pre- to post-UEL instructional approaches 